\title{
RBEP
}

\section{Ações afirmativas no ensino superior e o programa de bônus para ingresso nos cursos de graduação da Universidade Federal de Minas Gerais}

Maria do Carmo de Lacerda Peixoto

Mauro Mendes Braga

\section{Resumo}

Aborda as ações afirmativas na perspectiva da inclusão social e étnico-racial na educação superior. Analisa os dois primeiros anos da implantação, pela Universidade Federal de Minas Gerais, de um programa de bônus para escola pública e para declaração de cor ou raça no acesso aos seus cursos de graduação. São analisados os resultados dos vestibulares e os questionários socioeconômicos preenchidos pelos candidatos, verificando-se as alterações que se deram na composição de candidatos e aprovados, bem como os efeitos produzidos pelo programa para o aumento da inclusão na Universidade. Embora a inclusão promovida seja apenas parte de um caminho a ser trilhado para a efetividade dessa ação afirmativa, os resultados indicam que o programa de bônus propiciou alterações importantes no perfil dos aprovados no vestibular.

Palavras-chave: ação afirmativa; inclusão social; acesso ao ensino superior; inclusão racial. 


\section{Abstract \\ Affirmative actions in higher education and the bônus program for the admission in UFMG's graduation courses}

This paper addresses the affirmative action program under the perspective of social and ethno-racial inclusion in higher education. It analyzes the first two years of implementation, by the Federal University of Minas Gerais (UFMG), of a bonus program for admittance in public schools, and for the declaration of color or race, in its graduation courses. Results of the admittance exam and the socioeconomic forms filled out by applicants are evaluated, verifying the changes occurred in the composition of applicants and those admitted, as well as the effects generated by the program in the increase of the inclusion in the University. Despite the fact that the promoted inclusion is only part of the pathway to be covered verify the effectiveness of this affirmative action, the results indicate that the bonus program allowed important changes in the profile of those admitted to the University.

Keywords: affirmative action; social inclusion; higher education access, racial group inclusion.

\section{Introdução}

A abordagem do direito à diferença envolve um conjunto diversificado de questões que têm sido objeto do debate no campo intelectual e na sociedade. Focalizada numa perspectiva que complementa a noção de igualdade com a de equidade, sua operacionalização exige mais do que o estabelecimento de um padrão homogêneo de acesso aos direitos sociais, pois leva à avaliação do patamar de exclusão social dos indivíduos, com a análise das condições de igualdade, equidade e cidadania.

Respaldada em afirmações de Norberto Bobbio no livro Igualdade e liberdade, Moehlecke (2004) observa que não é a igualdade que atribui uma conotação positiva à enunciação de que todos os homens são ou nascem iguais, mas a sua extensão a todos os entes com os quais se está tratando e com relação a que eles são iguais, isto é, trata-se da igualdade em que e entre quem. Nesses termos, a implementação de políticas universalistas seria insuficiente para promover a inclusão, enquanto a sua focalização sobre grupos específicos seria um modo de tornar possível que seja dado mais a quem mais precisa e compensar ou reparar sequelas do passado. A equidade não seria apenas uma forma mais suave da igualdade, mas instrumento para estabelecer uma dialética com a igualdade e a justiça, ou seja, entre o certo, o justo e o equitativo, para a busca de um equilíbrio 
em que, com o objetivo de eliminar discriminações, se consideram tanto diferenças individuais de mérito quanto diferenças sociais.

Nessa perspectiva, as ações afirmativas se constituem um modo de focalização das políticas sociais voltadas para a promoção da inclusão social e compreendem

qualquer medida que aloca bens - tais como o ingresso em universidades, empregos, promoções, contratos públicos, empréstimos comerciais e o direito de comprar e vender terra - com base no pertencimento a um grupo específico, com o propósito de aumentar a proporção de membros desse grupo na força de trabalho, na classe empresarial, na população estudantil universitária e nos demais setores nos quais esses grupos estejam atualmente sub-representados em razão de discriminações passadas ou recentes (Feres, Zoninsein, 2006, p. 21).

Na avaliação que faz de políticas brasileiras para a redução da desigualdade, Zoninsein (2006) destaca que as ações afirmativas não podem ser concebidas como mero processo burocrático de realocação de recursos disponíveis, com investimentos de baixo custo e a expectativa de resultados automáticos. Para serem efetivas, é necessário considerar a gestão das instituições envolvidas, bem como a proposição de mecanismos institucionais destinados a maximizar seus benefícios potenciais. Para este autor, essas ações devem ser desenhadas para combater especificamente as desigualdades herdadas, que resultam não só da falta de recursos econômicos do indivíduo, mas também de sua identidade étnico/racial; exigem o investimento de quantidade significativa de diversas ordens de recursos, estando a maximização dos seus benefícios limitada pela extensão das desvantagens socioeconômicas e educacionais, pelo grau de resistência das comunidades acadêmicas, pelo volume de investimento desejado e possível que o governo e a sociedade civil mobilizam e pelos procedimentos institucionais aplicados para a implementação dessas políticas. ${ }^{1}$

Deve ser observado, ainda, que a implementação de políticas sociais na educação superior não se restringe à mera ampliação de oportunidades de acesso nem é instrumento suficiente para resolver a situação de desigualdade existente. Moehlecke (2004) destaca, com propriedade, que como raça e classe social se relacionam de modo complexo em diversos países, gerando uma combinação de discriminação racial e social, torna-se necessária a aplicação de medidas complementares às políticas de ação afirmativa, entre as quais se destaca a expansão e melhoria de qualidade da educação básica, tendo em vista que a democratização do acesso e a maior equidade na oferta da educação superior dependem também da associação entre a elevação da escolarização da população e a melhoria da qualidade da educação oferecida.

A implantação de políticas de ações afirmativas na educação superior no Brasil se intensificou a partir do início deste século, após ter sido aprovada em 28 de dezembro de 2000 a Lei estadual n 3.524, que determinou a introdução de cotas para estudantes de escolas públicas e para negros na Universidade do Estado do Rio de Janeiro (Wanderley, 2008). Nessa perspectiva, a Universidade Federal de Minas Gerais (UFMG) fez em 2003 a proposição de intensificar a criação de cursos e a ampliação de vagas no
${ }^{1}$ Uma discussão acerca da evolução da abordagem das ações afirmativas como políticas educacionais pode ser encontrada em Peixoto (2010). 
turno noturno, mas, por uma série de circunstâncias, essa proposta não teve êxito em atingir seus objetivos (Braga, Peixoto, 2008). Mais adiante, a Universidade aprovou em caráter experimental, por quatro anos, a aplicação de bônus adicionais ao desempenho no vestibular para estudantes oriundos de escolas públicas e que se declarem pretos ou pardos, política implantada para vigorar a partir de 2009.

A análise que será realizada neste artigo tem por objetivo apresentar os resultados das duas primeiras aplicações desse programa de bônus nos vestibulares da UFMG realizados em 2009 e 2010 para selecionar candidatos que iriam ingressar nos anos de 2010 e 2011. A implementação desse programa ocorreu concomitantemente com acentuada expansão de vagas decorrente da implantação, pelo Governo Federal, do Programa de Apoio aos Planos de Reestruturação e Expansão das Universidades Federais (Reuni), ambas as propostas com potencial para produzir alterações na composição socioeconômica e étnica do corpo discente da Universidade. Neste artigo não serão avaliadas as alterações nessa composição que resultaram do Reuni, limitando-se a discussão dessas alterações às eventuais mudanças observadas na concorrência entre candidatos e aprovados que podem ser associadas ao programa de bônus.

O artigo inicia com a caracterização do programa de bônus, para, a seguir, analisar as alterações ocorridas na composição socioeconômica e étnica de candidatos e aprovados. Os efeitos que o programa produziu para a inclusão na Universidade de maior proporção de estudantes procedentes de famílias situadas em faixas inferiores de renda familiar e que fizeram o ensino médio em escolas públicas, bem como de estudantes que se declararam como pretos ou pardos, são discutidos na última parte do texto.

\section{O programa de bônus da UFMG}

Após análise cuidadosa dos resultados dos vestibulares da UFMG de anos anteriores, o Conselho Universitário aprovou a adoção do programa de bônus. Nesse estudo, evidenciava-se a existência de candidatos oriundos de escolas públicas com bom desempenho na seleção, mas que deixavam de ser aprovados em razão de pequenas diferenças de notas. A esse fato se conjugava a presença de grande desequilíbrio, em diversos aspectos, quando se comparava o perfil dos candidatos inscritos com o dos aprovados; entre eles destacavam-se itens como a dependência administrativa da escola de ensino médio, renda familiar declarada, cor ou raça declarada e classe social. ${ }^{2}$ No vestibular de 2008, por exemplo, o grupo dos candidatos inscritos era composto por, aproximadamente, 49\% de egressos de escolas públicas e $39 \%$ de negros, ${ }^{3}$ enquanto no de aprovados, os percentuais foram 33\% e 30\%, respectivamente. Em cursos de prestígio social elevado, como Medicina, Odontologia, Ciências Econômicas, Arquitetura, Veterinária e em alguns ramos da Engenharia, esse desequilíbrio era ainda mais acentuado.

A formulação do programa de bônus partiu da explicitação de três premissas: em primeiro lugar, aumentar a proporção de estudantes 
aprovados egressos de escolas públicas e que se declaram como pretos ou pardos, de tal forma a, pelo menos, aproximá-los do observado no universo dos candidatos; em segundo lugar, produzir efeitos expressivos de inclusão social e étnico/racial sobre os cursos de elevado prestígio social, onde o alunado da UFMG é mais elitizado; em terceiro lugar, reverter a tendência de queda do número de candidatos oriundos da rede pública do ensino médio, observada a partir de 2002. Nesse ano, mais de 51 mil egressos de escola pública demandaram acesso aos cursos de graduação da UFMG, número que caiu para pouco mais de 32 mil em 2008.

Para atingir esses objetivos, foi aprovado o acréscimo dos percentuais de $10 \%$ ou de $15 \%$ à nota dos estudantes que, tendo requerido o benefício, comprovassem haver cursado todo o ensino médio e pelo menos as quatro últimas séries do ensino fundamental em escolas públicas. O percentual de $15 \%$ é atribuído àqueles que requereram o bônus e se autodeclararam pretos ou pardos quando da inscrição, declaração esta considerada suficiente para a atribuição do bônus; o tempo de escolaridade exigido, no entanto, deve ser comprovado após a aprovação no vestibular. Esses percentuais são aplicados às notas de ambas as etapas do vestibular.

\section{O programa de bônus e a demanda pelo vestibular}

Como a introdução do bônus no processo de seleção na UFMG visava contribuir para o aumento das chances de aprovação dos estudantes oriundos de escolas públicas, seria de se esperar que ele tivesse repercussão positiva sobre a demanda por vagas por parte desses candidatos. Essa expectativa se baseava na constatação de que, independentemente do ano de conclusão do ensino médio, o número de inscritos no vestibular da UFMG que fizeram o ensino médio em escolas públicas se situava em torno de $20 \%$ do total daqueles que concluíram esse nível de ensino em Minas Gerais no ano anterior ao da realização do exame. No caso da escola privada, essa proporção era superior a 100\%.

Ou seja, havia um enorme contingente de estudantes de escola pública do Estado de Minas Gerais que não se candidatavam à UFMG, talvez por considerarem a grande dificuldade para superar um nível de competição elevado, característico de uma seleção em que as vagas totais oferecidas se situavam em torno de $10 \%$, ou até menos, do número de candidatos. Com o acréscimo de pontos do bônus, esperava-se que pelo menos parte deles se sentisse estimulada a concorrer.

Para analisar as questões envolvidas nessa suposição, adotou-se um procedimento metodológico especial em função da disponibilidade dos dados que seriam trabalhados. Conquanto o bônus seja atribuído somente àqueles candidatos que requeiram o benefício e comprovem o tempo de escolaridade em escolas públicas, nos bancos de dados dos vestibulares da UFMG anteriores a 2009 não constavam informações relativas ao número de anos cursados no ensino fundamental. Por isso, na avaliação dos resultados do programa, será considerado apenas o tempo cursado 
no ensino médio, sendo que, para efeito das comparações com os anos anteriores, será considerado como egresso de escola pública o candidato que informou ter cursado o ensino médio em escola pública na totalidade ou em sua maior parte, pois este é o dado disponível. Essa decisão introduz certo grau de limitação à análise, mas, certamente, não a invalida.

\section{A concorrência conforme ensino médio em escola pública}

Os dados apresentados no Gráfico 1 tornam evidente que nem o bônus nem a expressiva expansão de vagas associada ao Reuni foram capazes de reverter as tendências que se observavam em relação à demanda por vagas na UFMG a partir de 2002. A tendência de queda anual do número de candidatos da rede pública é contínua, com algumas exceções, atingindo em 2010 pouco mais da metade daquela de 2002. Ao mesmo tempo, a demanda oriunda de estudantes das escolas privadas permaneceu praticamente constante ao longo do período, com média anual em torno de 32,5 mil candidatos.

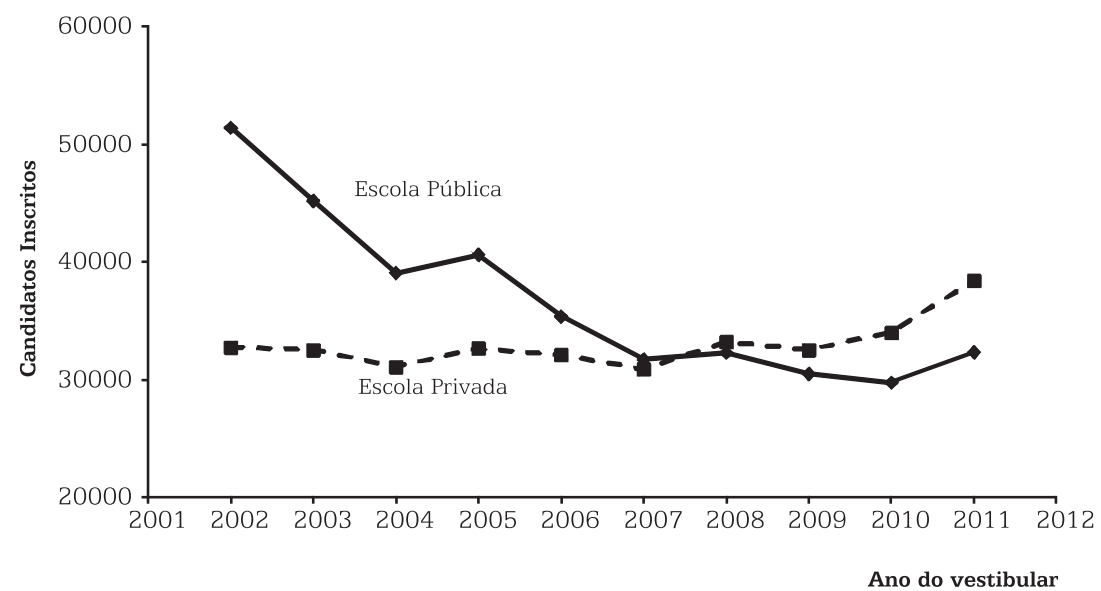

\section{Gráfico 1 - Candidatos Inscritos no Vestibular da UFMG, conforme Dependência Administrativa da Escola do Ensino Médio}

Esse decréscimo de demanda proveniente da rede pública ocorreu de forma generalizada, independentemente da organização administrativa da escola, fosse ela federal, estadual ou municipal, embora tenha sido mais pronunciado nas duas últimas, cujo número de inscritos em 2010 foi inferior à metade do verificado em 2002. Nas escolas federais, o total de inscritos em 2010 correspondeu a 4/5 do observado naquele ano. Em termos absolutos, no entanto, a grande redução de demanda se deu nas escolas estaduais, pois, se em 2002 quase 40 mil dos estudantes dessas

${ }^{4}$ A demanda pelos cursos da UFMG tem forte predominância (superior a 90\%) da população residente no Estado de Minas Gerais (Braga, Peixoto, 2006). escolas se inscreveram no vestibular da UFMG, em 2010 esse número não atingiu 24 mil.

As variações da demanda, contudo, não podem ser atribuídas às modificações no número de concluintes do ensino médio em Minas Gerais, ${ }^{4}$ 
que se deram em termos numéricos e, também, em relação ao total dos que concluíram esse nível de ensino em escolas públicas do Estado no ano anterior ao concurso. Em contrapartida, essa proporção tem aumentado continuamente no setor privado, com eventuais oscilações a partir de 2002. Esses dados são mostrados na Tabela 1, que compara, nos anos de 2002 e 2010, o número de candidatos inscritos no vestibular da UFMG, conforme o tipo de escola, em relação ao número dos que concluíram o ensino médio em Minas Gerais no ano anterior.

\section{Tabela 1 - Comparação do Número de Candidatos ao Vestibular da UFMG em 2002 e 2010 com o Número de Concluintes do Ensino Médio no Estado de Minas Gerais nos Anos Respectivamente Anteriores}

\begin{tabular}{|l|r|r|r|r|r|r|}
\hline \multirow{2}{*}{$\begin{array}{c}\text { Tipo de } \\
\text { escola }\end{array}$} & $\begin{array}{c}\text { UFMG } \\
\text { (A) }\end{array}$ & $\begin{array}{c}\text { Concluintes } \\
\text { MG (B) }\end{array}$ & $\begin{array}{c}\text { A/B } \\
(\%)\end{array}$ & $\begin{array}{c}\text { UFMG } \\
\text { (A) }\end{array}$ & $\begin{array}{c}\text { Concluintes } \\
\text { MG (B) }\end{array}$ & $\begin{array}{r}\text { A/B } \\
(\%)\end{array}$ \\
\hline Federal & 3.640 & 2.553 & 143 & 2.890 & 2.224 & 130 \\
\hline Estadual & 39.376 & 156.580 & 25 & 23.562 & 159.265 & 15 \\
\hline Municipal & 8.413 & 6.614 & 127 & 3.338 & 5.607 & 59 \\
\hline Privada & 32.747 & 32.556 & 101 & 34.010 & 26.128 & 130 \\
\hline
\end{tabular}

Algumas explicações ajudam a entender esse comportamento da demanda, entre elas o papel que a formação em nível técnico e tecnológico para acesso ao mercado de trabalho passou a despertar nos estudantes em função da ampliação e diversificação da oferta dessas modalidades. Pode ter também contribuído a ampliação e diversificação da oferta de educação superior pública e privada no Estado de Minas Gerais, principalmente a partir do final da década de 1990. A implantação do programa de bônus pela UFMG nesse cenário, como se verificou, não resultou na alteração do comportamento da demanda na direção esperada.

Como será observado mais adiante, no período de 2002 a 2009, políticas foram adotadas pela UFMG visando ampliar a inclusão social no acesso aos cursos de graduação e que produziram efeitos sobre o perfil dos estudantes aprovados. O que se observa a partir dos dados apresentados nessa tabela, no entanto, é que elas não foram eficazes no sentido de reverter essa tendência de queda na concorrência de candidatos do ensino médio público.

\section{A concorrência conforme a cor ou raça declarada}

No que se refere à cor ou raça declarada pelos candidatos a situação é diferente. Somente a partir de 2003 a UFMG incluiu esse item no questionário socioeconômico preenchido pelos candidatos quando da inscrição no exame. ${ }^{5}$ Os resultados dessas declarações permitiram observar que, nos primeiros anos, registrou-se aumento do percentual dos que se declaravam pretos ou pardos e redução da proporção dos que se identificavam
${ }^{5}$ Os candidatos respondem à pergunta "Qual é sua cor ou raça?" com as seguintes opções de resposta: branco, preto, pardo, amarelo, indígena, não desejo declarar. 
como brancos. Até 2008 esse perfil da concorrência se manteve estável e, como nos anos de 2009 e 2010 não se registraram alterações expressivas no que se refere à origem social dos candidatos, ${ }^{6}$ seria de se esperar que essa estabilidade do perfil se mantivesse também em relação à opção de cor ou raça.

Conforme ilustrado no Gráfico 2, entretanto, houve em 2009 pronunciado acréscimo percentual dos que se declararam pardos, enquanto na proporção de pretos o crescimento foi menos expressivo e decresceu o percentual de brancos em proporção correspondente ao aumento observado no somatório de pretos e pardos. ${ }^{7}$ Essas tendências se mantiveram quando do vestibular de 2010.

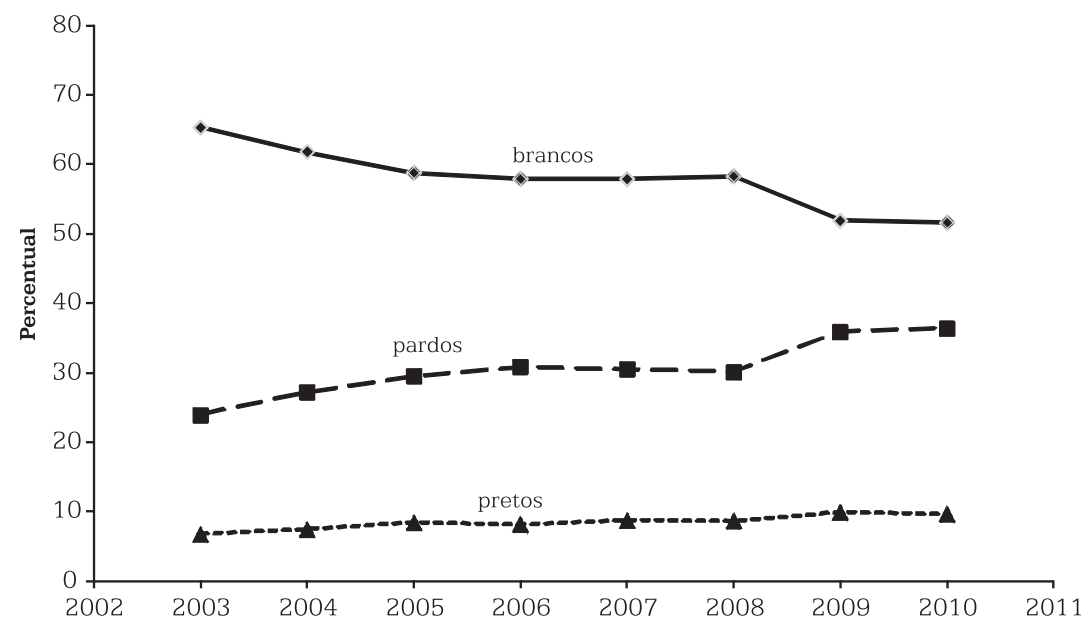

Gráfico 2 - Declaração de Cor ou Raça dos Candidatos ao Vestibular da UFMG

Obs.: Percentuais calculados excluindo os que optaram por não declarar a cor ou raça.

${ }^{6}$ Essa afirmativa se sustenta não só nos dados referentes à escola de ensino médio anteriormente apresentados, mas também nas informações abrangendo renda familiar, classificação Abipeme, cidade e Estado do candidato e nível de instrução dos pais, entre outras.

${ }^{7}$ Para maior concisão e clareza da exposição, não estão apresentadas as informações referentes a amarelos e indígenas, cuja participação entre os candidatos é bastante reduzida.
Essas observações sugerem que a existência do programa de bônus talvez tenha sido responsável por induzir alterações no perfil da declaração de cor ou raça dos candidatos ao vestibular sem que estas estivessem respaldadas por mudanças efetivas na situação dos candidatos. Outras evidências corroboram essa suposição e serão apresentadas a seguir.

Desde 2003 há registro de que cerca de um terço dos concorrentes ao vestibular da UFMG de um determinado ano também prestou o concurso no ano anterior, de tal forma que há cerca de 20 mil estudantes com declaração de cor ou raça feita em dois anos subsequentes (Braga, Peixoto, 2006). Assim sendo, buscou-se verificar se e como teria variado a declaração que foi prestada por um mesmo estudante nesses dois anos e analisaram-se os dados registrados nos períodos anterior e posterior à implantação do bônus. Para tanto, foi cotejado o mosaico de mudança de declaração de cor ou raça dos candidatos inscritos nos vestibulares de 2007 e de 2008 com aquele verificado para o grupo que se inscreveu em 2008 e em 2009.

O resultado desse confronto mostrou que, mesmo na ausência do bônus, foi expressivo o número de candidatos que, em 2008, mudaram 
a declaração prestada em 2007, em percentual que atingiu quase 20\% daqueles que se inscreveram nesses dois anos. Essa mudança, no entanto, parece ter sido aleatória, sem aparentemente expressar uma direção, de tal forma que o perfil do grupo nesse aspecto resultou praticamente o mesmo nesses dois anos, conforme registra a Tabela 2. Além disso, essa mudança de declaração ocorreu em percentual idêntico, 19\%, tanto entre os egressos da rede pública do ensino médio como entre os da rede privada.

Tabela 2 - Comparação Percentual das Declarações de Cor ou Raça Feitas pelas Mesmas Pessoas em Anos Subsequentes

\begin{tabular}{|c|c|c|c|c|c|}
\hline & Brancos & Pretos & Pardos & Amarelos & Índios \\
\hline \multicolumn{6}{|l|}{$\begin{array}{l}\text { Vestibular em } 2007 \\
\text { e } 2008\end{array}$} \\
\hline Resultado em 2007 & 56,2 & 7,4 & 26,8 & 1,9 & 0,4 \\
\hline Resultado em 2008 & 55,4 & 7,7 & 26,7 & 1,9 & 0,4 \\
\hline \multicolumn{6}{|l|}{$\begin{array}{l}\text { Vestibular em } 2008 \\
\text { e } 2009\end{array}$} \\
\hline Resultado em 2008 & 56,8 & 7,3 & 26,5 & 1,8 & 0,4 \\
\hline Resultado em 2009 & 48,1 & 9,5 & 34,3 & 1,5 & 0,2 \\
\hline
\end{tabular}

Obs.: Os valores da tabela não totalizam 100\% porque, em média, anualmente, $7 \%$ dos candidatos escolhem a opção "não desejo declarar" neste item do questionário.

Já no grupo que se inscreveu em 2008 e em 2009, o percentual de mudança da declaração foi maior, 25\%, mais acentuado, aparentemente, entre os concluintes da rede pública (30\%) do que entre os da rede privada (22\%). Além disso, essa mudança se fez de tal forma que imprimiu uma possível direção ao perfil da declaração, registrando-se o aumento na proporção de pardos e pretos e a redução na de brancos, resultando num perfil de cor ou raça completamente diferente nesses dois anos. ${ }^{8}$ Esses resultados podem ser indícios de que a alteração de comportamento dos candidatos teria ocorrido em razão da existência do programa de bônus. Serão analisados a seguir os resultados do programa de bônus nos vestibulares de 2009 e 2010.

\section{O programa de bônus e os resultados do vestibular}

Na Tabela 3 estão sumariados os bônus que foram concedidos em 2009 e 2010, verificando-se haver grande similaridade nos totais que foram atribuídos, correspondendo a pouco mais de $1 / 4$ do conjunto dos candidatos e a $55 \%$ daqueles que cursaram o ensino médio em escolas públicas. Este último percentual ter sido praticamente o mesmo nos dois anos é indicador do exame criterioso - feito pela Universidade - da documentação apresentada pelos que requereram o benefício para comprovar a escolaridade.

\footnotetext{
8 Apurações complementares indicam que entre os candidatos que prestaram vestibular em 2008 e em 2009, 2.509 podem ter alterado a declaração de cor ou raça que haviam prestado em 2008, provavelmente visando o bônus de 15\%. Desses, apenas 38 lograram aprovação em 2009 em razão desse adicional de 5\% nos pontos.
} 


\section{Tabela 3 - Súmula dos Bônus Concedidos nos Vestibulares da UFMG de 2009 e 2010}

\begin{tabular}{|c|c|c|c|c|c|c|}
\hline \multirow{2}{*}{ Ano } & \multirow{2}{*}{ Vagas } & \multicolumn{2}{|c|}{ Candidatos } & \multicolumn{3}{c|}{$\begin{array}{c}\text { Bônus concedidos / candidatos } \\
\text { escola pública }\end{array}$} \\
\cline { 3 - 7 } & & Total & Escola pública & $10 \%$ & $15 \%$ & Total (\%) \\
\hline 2009 & 5.911 & 63.281 & 30.538 & 21,6 & 33,7 & 55,3 \\
\hline 2010 & 6.598 & 63.980 & 29.790 & 20,7 & 35,0 & 55,7 \\
\hline
\end{tabular}

Também foi muito próxima, nos dois anos, a distribuição nas duas categorias do bônus: a de 15\%, aplicada àqueles que se identificaram como negros, e a de 10\%, aplicada àqueles que fizeram outras opções na declaração de cor ou raça. Entre os egressos das escolas públicas, os das escolas federais é que foram menos contemplados, totalizando 42\% no biênio, enquanto nas escolas estaduais e municipais os percentuais correspondentes foram, respectivamente, 57\% e 56\%. O bônus de 15\% predominou nos três tipos de escolas em 2010, com frequência de 64\% nas federais, 62\% nas estaduais e 67\% nas municipais. Considerando-se as faixas de renda familiar, a diferença foi acentuada tanto entre os não bonistas como entre os bonistas. Para os primeiros, mais de 80\% apresentavam renda mensal familiar de até 15 salários mínimos (SM) e, para os segundos, mais de $80 \%$ declararam possuir uma renda mensal familiar de até 5 SM, valores observados tanto em 2009 como em 2010. Entre os que receberam o bônus, no entanto, a distribuição dessa renda foi similar em ambos os anos, pois, tanto no grupo que obteve $10 \%$ como no que obteve 15\% de acréscimo, ela se limitou a 5 salários mínimos para mais de 80\%.

Mais importante que averiguar como se deu a concessão do bônus é saber os efeitos que ele produziu nos resultados do concurso. Isto é, entre os aprovados, quantos foram os beneficiados e, especialmente, quantos e como se distribuíram aqueles que só foram aprovados devido ao bônus.

Esses efeitos estão sintetizados nas Tabelas 4 e 5, sendo na primeira delas informada a participação de candidatos aprovados que receberam o bônus e a daqueles que dependeram dele para a aprovação. Na segunda estão os dados relativos a esses últimos, conforme a escola de ensino médio e a cor/raça declarada.

Tabela 4 - Bônus Concedidos e Aprovação no Vestibular

\begin{tabular}{|c|c|c|c|c|c|}
\hline Período & Vagas & $\begin{array}{c}\text { Bonistas } \\
\text { aprovados }\end{array}$ & $\begin{array}{c}\text { Percentual/ } \\
\text { Vagas }\end{array}$ & $\begin{array}{c}\text { Dependeram } \\
\text { do bônus }\end{array}$ & $\begin{array}{c}\text { Percentual/ } \\
\text { Vagas }\end{array}$ \\
\hline 2009-2010 & 12.509 & 4.224 & 33,8 & $1.424^{*}$ & 11,4 \\
\hline
\end{tabular}

*Neste dado não estão incluídos os aprovados do curso de Música na modalidade bacharelado.

Entre os bonistas aprovados, apenas 1/3 dependeu do bônus para a aprovação, estando os demais habilitados ao ingresso na UFMG mesmo na ausência do benefício. O provimento de vagas determinado pelo bônus 
foi de pouco mais de 10\%, sendo a grande maioria egressa de escolas estaduais.

Tabela 5 - Bonistas que Dependeram do Benefício para a Aprovação

\begin{tabular}{|l|c|c|c|c|c|c|c|}
\hline \multirow{2}{*}{ 2009-2010 } & \multirow{2}{*}{ Total } & \multicolumn{3}{|c|}{ Escola de Origem } & \multicolumn{3}{c|}{ Cor ou Raça Declarada } \\
\cline { 3 - 9 } & & Federal & Estadual & Municipal & Preta & Parda & Outra \\
\hline Número & 1.424 & 273 & 997 & 154 & 212 & 906 & 308 \\
\hline$\%$ & 100,0 & 19,2 & 70,0 & 10,8 & 14,9 & 63,6 & 21,6 \\
\hline
\end{tabular}

No que concerne à declaração de cor ou raça, a maior parte dos candidatos que dependeram do benefício para aprovação foram os que se declararam pardos; em conjunto com os pretos, eles correspondem a mais de $3 / 4$ dos candidatos aprovados em razão do programa, ou seja, mais de 3/4 dos que necessitaram do bônus para a aprovação receberam acréscimo de $15 \%$ nos pontos obtidos. Desse grupo, contudo, mais de 2/3 também teriam sido aprovados se tivessem recebido apenas o bônus de $10 \%$. Pode-se concluir que, entre os candidatos que dependeram do benefício para serem aprovados, cerca de 3/4 teriam sido (ou foram) aprovados apenas com o acréscimo de 10\%. Convém observar ainda que 18\% dos candidatos que dependeram do bônus para o ingresso fizeram sua declaração como brancos, percentual maior do que o de candidatos negros.

\section{Alterações no perfil de renda familiar}

A despeito de diversas evidências de que as variáveis organização administrativa da escola e cor ou raça declarada, com base nas quais foi formatado o programa de bônus, guardam correlação com a situação socioeconômica do estudante e de sua família, persistem dúvidas sobre a efetividade desse tipo de política. Considerando-se que são aprovados apenas 1/4 dos que foram beneficiados pelo bônus, a renda familiar desse grupo poderia ser mais elevada em relação aos que foram beneficiados e não foram classificados no vestibular.

Para sanar essa dúvida, comparou-se o histograma de renda familiar desses dois grupos. Com o objetivo de facilitar a apresentação dos dados, os bonistas aprovados em razão do bônus foram denominados Incluídos e os não bonistas que deixaram de ser aprovados devido ao bônus foram denominados Excluídos. Tal comparação foi feita com os dados desagregados por ano do concurso, sem atualização monetária das faixas de renda, conforme a variação do salário mínimo entre os dois anos considerados (Gráfico 3).

Os dados de 2009 e 2010 apresentados no Gráfico 3 apontam para uma possível diferença de renda familiar entre os grupos de estudantes bonistas classificados e não classificados na lista de aprovados. Essa diferença leva a observar que: a) para mais de 70\% dos Incluídos, a renda 
familiar é inferior a 5 SM, enquanto que no grupo Excluídos a percentagem correspondente é de 30\%; e b) menos de 1\% dos Incluídos informaram renda familiar superior a $20 \mathrm{SM}$, enquanto no outro grupo esse percentual é superior a $10 \%$.
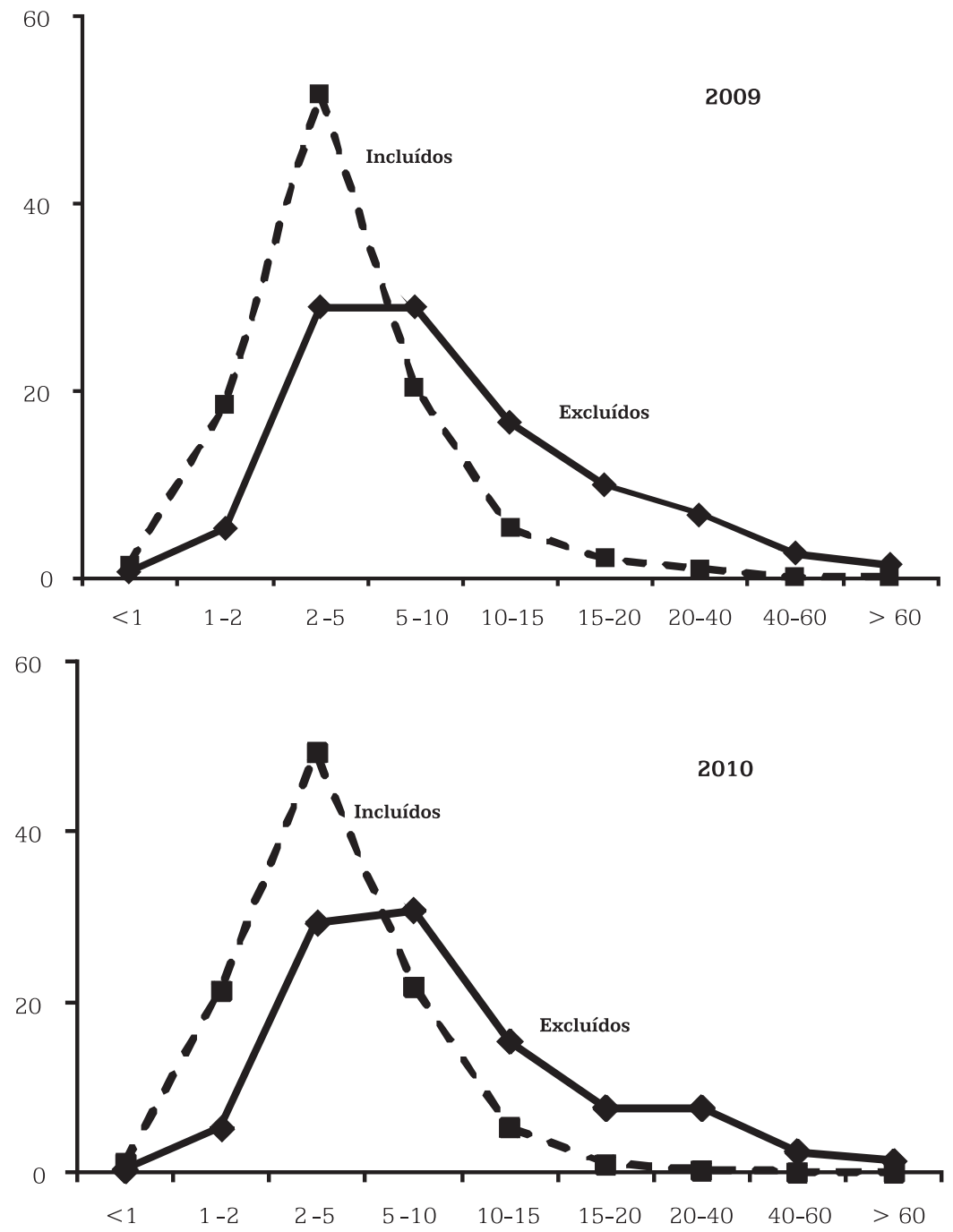

Gráfico 3 - Comparação da Renda Familiar, em Salários Mínimos, dos Grupos de Candidatos Bonistas Classificados e Não Classificados na Lista de Aprovados - 2009 e 2010

As diferenças citadas também estão presentes quando se consideram os cursos, sendo ainda maiores naqueles de elevado prestígio social, a exemplo do de Medicina, que nos dois anos considerados admitiu 155 candidatos bonistas para o total de 640 vagas. Nesse curso, a renda familiar média do grupo Incluídos é três vezes menor que a do Excluídos e mais de 60\% deles declararam renda familiar de até 5 SM, enquanto que o percentual correspondente no grupo Excluídos é pouco maior que 10\%. Do mesmo modo, 
apenas 1\% dos estudantes do grupo Incluídos informaram renda familiar superior a 20 SM, percentual que atingiu 20\% no outro grupo. Esses resultados podem ser indícios de que a Universidade foi bem sucedida em atingir o objetivo de, com o programa de bônus, produzir alteração na combinação das variáveis escola pública e declaração de cor ou raça, com a situação socioeconômica do estudante na composição do corpo discente.

\section{Alterações na composição socioeconômica dos cursos ofertados pela UFMG}

No debate suscitado ao longo do processo de aprovação do programa de bônus, a proposta foi alvo de algumas objeções, entre elas a de que o efeito de inclusão social que o programa poderia promover seria justamente naquelas áreas do conhecimento em que a Universidade já admitia uma proporção elevada de estudantes com nível de renda familiar mais baixo. Assim sendo, o efeito do programa seria apenas marginal em cursos de elevado prestígio social, como Medicina, Engenharia, Direito e Odontologia.

Para averiguar a veracidade dessa proposição, serão denominados de carreiras cursos que levam à mesma habilitação profissional, independentemente do turno oferecido. Apesar de a abordagem dos turnos em conjunto implicar o tratamento de perfis diferenciados de estudantes sob uma mesma denominação, esse recurso analítico não reduz a sua contribuição para explicitar o tema ora em estudo. Do mesmo modo, para maior concisão da análise, o conjunto dos cursos de Engenharia oferecidos pela UFMG será considerado como uma única carreira, denominada Engenharias. O fato de haver bastante homogeneidade na composição socieconômica dos estudantes desse grupo de cursos contribui para essa decisão.

A Tabela 6 apresenta as oito carreiras que receberam $51 \%$ dos bonistas. O que se verifica é que, ao contrário da hipótese surgida no debate, grande parte dos bonistas ingressaram em carreiras "tradicionais" e de elevado prestígio social, excetuando-se Letras nesse segundo caso.

Tabela 6 - Carreiras em que foi Maior o Número de Vagas Providas por Aprovados Classificados pelo Bônus no Período 2009-2010

\begin{tabular}{|c|c|c|c|c|c|}
\hline \multirow{2}{*}{ Carreira } & \multicolumn{2}{|c|}{ Vagas } & \multirow{2}{*}{ Carreira } & \multicolumn{2}{|c|}{ Vagas } \\
\hline & Ofertadas & Bônus & & Ofertadas & Bônus* \\
\hline Engenharias & 2.160 & 211 & Ciências Biológicas & 400 & 49 \\
\hline Medicina & 640 & 155 & Farmácia & 344 & 47 \\
\hline Direito & 800 & 111 & Veterinária & 240 & 37 \\
\hline Letras & 840 & 79 & Odontologia & 288 & 34 \\
\hline
\end{tabular}

* Vagas preenchidas por candidatos que dependeram do acréscimo do bônus.

Não se deve concluir que o efeito do bônus causou alterações profundas no conjunto dessas carreiras, dado que esses bonistas 
representam apenas 13\% do total das vagas oferecidas. O que se pode dizer é que, em números absolutos, há mais bonistas aprovados nessas carreiras, em razão do programa, do que nas demais. O efeito do benefício foi particularmente expressivo em Medicina, onde quase $25 \%$ das vagas tiveram o provimento determinado pelo bônus, percentual que em nenhuma outra alcançou 20\%.

Em algumas carreiras o efeito do bônus foi muito pequeno. Isso ocorreu de forma genérica na área de artes, onde Artes Visuais, Música e Teatro foram pouquíssimo afetadas. Deve ser observado, contudo, que em todas essas carreiras a proporção de estudantes admitidos oriundos de escolas públicas já se situa em proporção quase sempre superior a ou próxima de 50\%.

Além da área de artes, o bônus teve impacto muito reduzido nas carreiras de Geologia, Arquitetura e Ciências Econômicas, com características que merecem comentários. Na primeira delas, a composição socioeconômica dos alunos vem progressivamente se tornando mais elitizada, mas ainda se registra cerca de 30\% deles provenientes de escola pública no ensino médio. Arquitetura, por sua vez, tem sua trajetória na Universidade caracterizada como uma das carreiras que menos recebem estudantes de escolas públicas. Essa trajetória é própria da sua oferta diurna, e, com a abertura do turno noturno em 2010, essa característica vem assumindo matizes um pouco diferentes, uma vez que mais da metade dos estudantes admitidos nesse turno fizeram o ensino médio em escolas públicas. Já a carreira de Ciências Econômicas vem se transformando, ao longo do tempo, na mais elitizada da UFMG. Ela admite menos de 20\% de estudantes oriundos de escolas públicas e é onde se concentram, em maior número, estudantes provenientes das faixas de renda elevadas.

\section{Efeitos do programa de bônus para a inclusão social e de cor ou raça}

Um dos propósitos do programa de bônus, como já foi mencionado, era aproximar o perfil socioeconômico dos aprovados no vestibular ao dos candidatos. Para descrever sinteticamente as alterações nesses perfis, serão analisadas as duas variáveis nas quais se baseia o programa. Quanto à cor ou raça declarada pelos estudantes, os negros (pretos e pardos) serão contrapostos ao conjunto das demais opções de declaração, o que significa que essa comparação se faz, na prática, entre brancos e negros, dado que aqueles que se identificam como amarelos ou indígenas geralmente não alcançam, juntos, 3\% do total. O aumento de estudantes egressos de escolas públicas entre os aprovados será identificado como sendo efeito de inclusão social, e o aumento de estudantes que se identificam como negros será considerado como sendo efeito de inclusão de cor ou raça. Ressalve-se que o termo inclusão está referenciado exclusivamente ao aumento das proporções em que se deu o ingresso de membros desses dois grupos nos cursos de graduação da UFMG. 
Como já foi dito, a Universidade tinha implementado políticas de inclusão focalizadas na ampliação de vagas no turno da noite e mais concentradas na oferta de cursos de licenciatura. Essa política mostrou que, à medida em que aumentava a proporção de egressos da rede pública do ensino médio e de estudantes que se identificavam como negros, crescia também a proporção daqueles oriundos de camadas populares da sociedade, os quais, até então, enfrentavam dificuldades maiores no acesso à educação superior.

As variáveis analisadas a seguir permitem identificar expressivas diferenças socioeconômicas entre os dois grupos de estudantes. $\mathrm{Na}$ comparação entre egressos de escolas públicas e privadas, mais de 3/4 dos candidatos ao vestibular da UFMG que fizeram o ensino médio em escolas públicas declararam renda familiar de até $5 \mathrm{SM}$ e apenas cerca de $1 \%$ informou renda superior a 20 SM, enquanto nos da rede privada os números correspondentes são 1/4 e 15\%. As diferenças observadas no item declaração de cor ou raça são um pouco menores, mas também expressivas. Entre os que se declararam brancos, $40 \%$ têm renda familiar inferior a 5 SM e 10\%, superior a 20 SM, percentuais estes que, entre os negros, são, respectivamente, $65 \%$ e $3 \% .{ }^{9}$

Anteriormente a 2009, observava-se uma diferença acentuada na distribuição dos egressos de escolas públicas em relação aos das escolas privadas, quando se comparava o universo dos candidatos com a lista de aprovados. Os concluintes do ensino médio privado superavam os do público em cerca de 20 pontos percentuais, ocorrendo o inverso com os que concluíram o ensino público. Situação similar ocorria na comparação entre brancos e negros, sendo que, nesse caso, a sobrerrepresentação dos primeiros na lista de aprovados era de cerca de 10 pontos percentuais. Os dados pertinentes estão apresentados nas Tabelas 7, 8, 9, 10 e 11, que serão comentadas mais adiante.

Avaliar o impacto do bônus na redução dessas diferenças não se restringe a comparar os resultados observados em 2009 e 2010 com os dos anos anteriores, dado que ele foi implementado concomitantemente a um amplo programa de expansão de vagas, onde a maior parte da expansão ocorreu no turno da noite. Como esses são dois componentes com potencial para proporcionar maior inclusão social e de cor ou raça, por essa razão, além de comparar os resultados de anos anteriores e posteriores à implantação do programa de bônus, será necessário simular, também, aqueles que poderiam ser observados em 2009 e 2010 caso o programa não existisse. Essa simulação implica, porém, uma limitação.

O vestibular da UFMG ocorre em duas etapas, sendo selecionados para a segunda os candidatos com melhor classificação na primeira, o que resulta, em média, na indicação, a cada ano, de um total de candidatos correspondente a cerca de 2,5 vezes o número de vagas oferecidas. No período considerado, isso implicou selecionar para a segunda etapa entre $17 \%$ e $25 \%$ dos candidatos, sendo tanto maior esse percentual quanto maior for o número de vagas. Por ser aplicado nesses dois momentos, o bônus afeta ambos os resultados. Assim, a simulação mencionada
${ }^{9}$ Os valores mencionados nesse parágrafo são aproximados e se aplicam a, pelo menos, cinco vestibulares anteriores à implantação do bônus, ou seja, aos anos de 2003 a 2008. 
alcançará apenas os resultados dos candidatos que foram selecionados para a segunda etapa, porque, na ausência do bônus, a lista dos aprovados para este segundo momento não seria a mesma, impossibilitando simular o desempenho de um candidato que não prestou essas provas. Os dados referentes a essas simulações, com a limitação apontada, também estão registrados nas Tabelas 7 e 10, analisadas a seguir.

\section{Efeitos de inclusão social}

A Tabela 7 mostra que, após a implantação do bônus e a expansão de vagas do Reuni, a sub-representação dos egressos de escolas públicas na relação dos aprovados foi reduzida em 14 pontos percentuais em 2009, quando comparada à média dos cinco anos anteriores, redução que atingiu 16,3 pontos percentuais em 2010. ${ }^{10}$ Esses valores são bastante expressivos, destacando-se ainda que, em 2010, o percentual dos egressos da rede pública na lista de aprovados aproximou-se bastante daquele que estava presente entre os inscritos.

Tabela 7 - Percentuais Observados entre Candidatos e Aprovados, conforme o Tipo de Escola do Ensino Médio

\begin{tabular}{|c|c|c|c|c|c|c|}
\hline & \multicolumn{3}{|c|}{ Escola Pública } & \multicolumn{3}{|c|}{ Escola Privada } \\
\hline & Aprovados & Inscritos & Diferença & Aprovados & Inscritos & Diferença \\
\hline \multicolumn{7}{|l|}{$\begin{array}{l}2004 \mathrm{a} \\
2008\end{array}$} \\
\hline $\begin{array}{l}\text { Média de } \\
\text { resultados }\end{array}$ & 34,7 & 52,4 & $-17,7$ & 65,1 & 47,1 & 17,9 \\
\hline \multicolumn{7}{|l|}{2009} \\
\hline Resultado & 44,6 & 48,3 & $-3,7$ & 55,2 & 51,4 & 3,8 \\
\hline Simulação & 35,2 & 48,3 & $-13,1$ & 64,6 & 51,4 & 13,2 \\
\hline \multicolumn{7}{|l|}{2010} \\
\hline Resultado & 45,2 & 46,6 & $-1,4$ & 54,6 & 53,2 & 1,4 \\
\hline Simulação & 36,5 & 46,6 & $-10,1$ & 63,3 & 53,2 & 10,1 \\
\hline
\end{tabular}

Os resultados aqui simulados para uma situação de inexistência do bônus permitem supor que a contribuição desse programa teria sido bem maior para o efeito de inclusão social do que foi a da expansão de vagas. Em 2009, o número de egressos de escolas públicas aprovados no vestibular foi de 9,9 pontos percentuais, valor superior ao observado na média dos anos 2004-2008. Esse aumento teria sido de apenas 0,5 ponto percentual

${ }^{10}$ Nessa tabela, a soma dos percentuais das colunas Diferença de uma mesma linha nem sempre resulta em zero, em razão da existência dos assim chamados estudantes de cursos livres, que concluem o ensino médio em cursos supletivos. caso não existisse o bônus, tendo a contribuição exclusiva do programa para esse acréscimo atingido 9,4 pontos percentuais. Em 2010 o efeito se repetiu, sendo agora esses valores 10,5, 1,8 e 8,7 pontos percentuais.

Nos diferentes tipos de dependências administrativas das escolas públicas, as características em relação a esses resultados são diversas. 
Os dados pertinentes são apresentados na Tabela 8, não estando nela incluídos aqueles referentes às simulações, desnecessários à discussão que se fará.

Tabela 8 - Percentuais Observados entre Inscritos e Aprovados, conforme a Dependência Administrativa da Escola Pública

\begin{tabular}{lr|r|r|r|r|r|r|r|r|}
\multirow{2}{*}{ Período } & \multicolumn{3}{c}{ Federal } & \multicolumn{3}{c|}{ Estadual } & \multicolumn{3}{c|}{ Municipal } \\
\cline { 2 - 11 } & Aprov. & Inscr. & Diferença & Aprov. & Inscr. & Diferença & Aprov. & Inscr. & Diferença \\
\hline $2004-2008$ & 10,9 & 4,2 & 6,7 & 19,2 & 40,8 & $-21,6$ & 4,5 & 7,4 & $-2,9$ \\
\hline 2009 & 11,0 & 4,5 & 6,5 & 28,6 & 38,0 & $-9,4$ & 5,0 & 5,8 & $-0,8$ \\
\hline 2010 & 9,9 & 4,5 & 5,4 & 29,8 & 36,8 & $-7,0$ & 5,5 & 5,3 & 0,2 \\
\hline
\end{tabular}

Os egressos do ensino médio das escolas federais sempre estiveram sobrerrepresentados na relação de aprovados em comparação com a dos inscritos. Como a regulamentação do programa de bônus não restringe o acesso ao benefício por tipo de escola pública, seria possível prognosticar que essa sobrerrepresentação iria ser ampliada; ocorreu o contrário, contudo, ainda que persista presença mais acentuada. Por sua vez, o conjunto das ações de inclusão adotado pela UFMG em 2010 pôs fim à sub-representação dos egressos de escolas municipais entre os aprovados, mas os alunos das escolas estaduais mantiveram sub-representação elevada, embora sua força tenha sido atenuada.

Dados esses resultados, seria adequado pretender que o bônus não deveria ser aplicado para os egressos das escolas federais? Para tomar uma decisão desse tipo, seria preciso analisar os efeitos que ela produziria na distribuição dos bônus entre os demais candidatos. Poder-se-ia imaginar, a princípio, que tal decisão iria resultar em maior favorecimento dos estudantes das escolas estaduais e municipais, porque apenas eles seriam beneficiários do programa. Análises preliminares sugerem, contudo, que isso não iria ocorrer, dado que os maiores beneficiados de uma eventual exclusão do programa de bônus dos estudantes das escolas federais talvez fossem os egressos das escolas privadas. A título de exemplo, um exercício foi feito para os resultados do curso de Medicina em 2010, ano em que foram aprovados para ele 37 egressos de escolas federais que dependeram do bônus para a aprovação. Na hipótese em análise, esses 37 estudantes viriam a ser substituídos na lista de aprovados por quatro outros estudantes de escolas federais, por três de escolas estaduais e por 30 de escolas privadas.

Tendo em vista esses números, é interessante proceder a uma comparação entre os indicadores socioeconômicos dos estudantes oriundos de escolas privadas com os dos seus colegas das escolas federais aprovados para esse curso em 2010. Esses indicadores estão sintetizados na Tabela 9. 
Tabela 9 - Indicadores Socioeconômicos de Aprovados do Curso de Medicina Egressos de Escolas Públicas Federais e Privadas - 2010

\begin{tabular}{|l|c|c|}
\hline \multirow{2}{*}{\multicolumn{1}{c}{ Variável }} & \multicolumn{2}{c|}{ Tipo de Escola de Ensino Médio } \\
\cline { 2 - 3 } & Pública Federal & Privada \\
\hline Renda familiar até 5 SM & $43 \%$ & $25 \%$ \\
\hline Renda familiar superior a 20 SM & $5 \%$ & $14 \%$ \\
\hline Classe Abipeme A ou B & $49 \%$ & $67 \%$ \\
\hline
\end{tabular}

Como se observa, são grandes as diferenças na composição socioeconômica dos dois grupos. No que seria excluído da lista de aprovados, 17 estudantes têm renda familiar de até 5 SM, enquanto no grupo que seria incluído ela é de 7 SM. Desse modo, em lugar de proporcionar o ingresso de mais alunos de escola pública e com renda familiar mais baixa, retirar o acesso ao bônus dos estudantes das escolas federais iria cancelar parte dos efeitos de inclusão social que o programa atingiu.

\section{Efeitos de inclusão de cor ou raça}

A Tabela 10 apresenta uma síntese das informações relativas à inclusão de cor ou raça, que se deu em consequência do programa de bônus.

Tabela 10 - Percentuais Observados entre Candidatos e Aprovados, conforme a Declaração de Raça ou Cor

\begin{tabular}{c|c|c|c|c|c|c|}
\hline \multirow{2}{*}{ Período } & \multicolumn{3}{|c|}{ Negros } & \multicolumn{3}{c|}{ Brancos } \\
\cline { 2 - 7 } & Aprovados & Inscritos & Diferença & Aprovados & Inscritos & Diferença \\
\hline $\begin{array}{l}\text { De 2004 a } \\
\text { 2008 }\end{array}$ & & & & & & \\
$\begin{array}{c}\text { Resultados } \\
\text { Médios }\end{array}$ & 28,9 & 37,9 & $-9,0$ & 69,2 & 58,9 & 10,3 \\
\hline \begin{tabular}{c|c|c|c|c|c|} 
2009 \\
Resultado
\end{tabular} & 46,0 & 45,8 & 0,2 & 52,4 & 51,9 & 0,5 \\
\hline $\begin{array}{c}\text { Simulação } \\
\text { 2010 }\end{array}$ & 40,6 & 45,8 & $-5,2$ & 57,7 & 51,9 & 5,8 \\
\hline Resultado & 49,6 & 46,0 & 3,6 & 48,7 & 51,6 & $-2,9$ \\
Simulação & 40,5 & 46,0 & $-5,5$ & 53,7 & 51,6 & 2,1 \\
\hline
\end{tabular}

Nessa análise é preciso certa cautela, considerando o efeito de indução, mencionado anteriormente, que o programa poderia ter gerado sobre a declaração de cor ou raça, isso porque não é possível, nesse caso, determinar se o candidato que se identificou como negro de fato assim se considera ou se tal declaração foi motivada pela possibilidade de obter o bônus de 15\%. 
O fato é que a sub-representação dos negros na relação de aprovados, próxima de 10 pontos percentuais, sem grande oscilação anual no período 2004-2008, transformou-se, em 2010, em uma aparente sobrerrepresentação de quase 4 pontos percentuais. Por sua vez, os brancos, cuja maior proporção estava na faixa de 10 pontos percentuais, passaram, em 2010, a uma possível sub-representação de cerca de 3 pontos percentuais. Considerando a hipótese de que tais resultados correspondam à realidade dos fatos, esses dados indicariam que as políticas adotadas pela UFMG foram capazes de produzir inclusão de cor ou raça para o conjunto de seus cursos em proporção aparentemente superior à esperada.

Procedendo novamente à simulação do que teria ocorrido no caso de não existir o bônus, constata-se uma indicação de que, ao contrário do verificado quando da análise da inclusão de alunos da escola pública, o papel desempenhado pela expansão de vagas teria sido mais importante do que o do programa de bônus. Em comparação com o período 20042008, a proporção de negros que ingressaram em 2009 aumentou em 17,1 pontos percentuais, valor que seria de 11,7 pontos percentuais caso o bônus não tivesse existido. Esse programa contribuiu, portanto, com 5,4 pontos percentuais para o acréscimo verificado. Em 2010, esses mesmos valores são 20,7, 11,6 e 9,1 pontos percentuais.

Considerando-se os efeitos produzidos no âmbito dos cursos, verifica-se que o programa de bônus e a expansão de vagas acarretaram pronunciado aumento, na maioria das carreiras, na proporção de estudantes que se identificam como negros, quando se comparam os dois anos anteriores com os dois posteriores à adoção do bônus. No biênio 2007/2008, 18 das carreiras ofertadas no vestibular registraram, entre os aprovados, percentual de negros inferior a $30 \%$.

Como mostra a Tabela 11, no biênio 2009/2010, muitas das carreiras registraram aumento na proporção de negros, aumento que se aproximou de ou até mesmo foi superior a 20 pontos percentuais.

Tabela 11 - Carreiras com Percentuais mais Elevados de Vagas Providas pelo Acréscimo do Bônus de 15\%

\begin{tabular}{|l|c|c|}
\hline \multicolumn{1}{|c|}{ Carreiras } & 2007-2008 & 2009-2010 \\
\hline Administração & 26 & 47 \\
\hline Farmácia & 21 & 51 \\
\hline Medicina & 27 & 46 \\
\hline Odontologia & 23 & 47 \\
\hline Biblioteconomia & 46 & 63 \\
\hline Enfermagem & 40 & 58 \\
\hline Pedagogia & 43 & 67 \\
\hline
\end{tabular}

O expressivo aumento na proporção de estudantes que se identificaram como negros fez com que sua presença em algumas 
carreiras tradicionais e de elevado prestígio social se aproximasse de ou superasse os 50\%. Apenas na carreira de Ciências Econômicas a proporção de negros aprovados foi inferior a 30\%, com aumento de apenas 6 pontos percentuais, o que confirma o já mencionado efeito muito reduzido que o programa de bônus produziu sobre ela. Outras três carreiras registraram proporção de negros entre 30\% e 40\%: Arquitetura (35\%), Ciência da Computação (32\%) e Geologia (35\%). Na Arquitetura, cuja proporção de negros aumentou 16 pontos percentuais, quase todo esse aumento deve ser creditado à criação do curso noturno, no qual ingressaram mais de 50\% dos autodeclarados negros. No diurno, no período 2009-2010, o percentual de negros foi de $21 \%$, valor que foi apenas 2 pontos percentuais a mais que o registrado no biênio anterior. Na Ciência da Computação, que não expandiu vagas, o resultado do bônus não produziu alteração na proporção de negros admitidos. Geologia, finalmente, foi a única carreira em que se registrou diminuição na proporção de negros admitidos, embora de apenas 2 pontos percentuais.

O efeito de inclusão de cor ou raça foi mais pronunciado no turno da noite, já caracterizado pela maior concentração de estudantes negros. Em 2007-2008 foram admitidos 28\% desses alunos nos cursos diurnos e 37\%, nos noturnos, percentuais que em 2009 e 2010 foram, respectivamente, $43 \%$ e 56\%, aumentando de 9 para 13 pontos percentuais a diferença na presença de negros entre os cursos noturnos e os diurnos.

Por ser relevante ao debate do tema da inclusão de cor ou raça, são apresentadas na Tabela 12 as informações desagregadas para pretos e pardos.

Tabela 12 - Percentuais Observados entre Candidatos e Aprovados cuja Declaração de Cor ou Raça foi como Pretos ou Pardos

\begin{tabular}{|l|c|c|c|c|c|c|}
\hline \multirow{2}{*}{ Período } & \multicolumn{3}{|c|}{ Pretos } & \multicolumn{3}{c|}{ Pardos } \\
\cline { 2 - 8 } & Aprovados & Inscritos & Diferença & Aprovados & Inscritos & Diferença \\
\hline $2004-2008$ & 4,0 & 8,2 & $-4,2$ & 24,9 & 29,6 & $-4,7$ \\
\hline 2009 & 8,4 & 9,9 & $-1,5$ & 37,6 & 35,9 & 1,7 \\
\hline 2010 & 8,8 & 9,6 & $-0,8$ & 40,8 & 36,4 & 4,4 \\
\hline
\end{tabular}

Os dados da tabela indicam que, anteriormente ao programa de bônus, pretos e pardos se encontravam sub-representados, em proporções similares, na relação de aprovados. Com o advento do bônus, a sub-representação dos pretos foi atenuada, contudo, a situação dos pardos se alterou bastante, dado que eles passaram a estar em maior proporção na lista de aprovados, atingindo em 2010 valor superior a 4 pontos percentuais. Esse resultado sugere novamente a suposição de que o bônus teria estimulado candidatos que, mesmo não se sentindo como pardos, assim se declararam quando da inscrição no vestibular. 


\section{Conclusão}

A análise da inclusão social e de cor ou raça realizada neste artigo compreende apenas o estudo dos efeitos do programa de bônus para ampliar o acesso de estudantes de escola pública e de negros na UFMG, o que sinaliza para apenas parte do problema. O programa de bônus buscou preservar o princípio do mérito na seleção, de modo a assegurar que o estudante aprovado no vestibular pudesse ter bom desempenho no curso e obter, ao final, formação similar à de seus colegas não bonistas. É preciso ressalvar, contudo, que uma série de variáveis não abordadas neste artigo interfere nesse desempenho ao longo da graduação, e, por isso, demandam análise mais aprofundada.

Diante do que foi aqui tratado, algumas conclusões podem ser relacionadas, como se segue.

- Conforme ilustrado no Gráfico 1, as ações desenvolvidas pela UFMG no período 2009-2010 não foram capazes de reverter a tendência de diminuição do número de concorrentes ao vestibular oriundos de escolas públicas.

- O preenchimento de vagas por meio da concessão de bônus atingiu em torno de $35 \%$ das que foram oferecidas no período analisado, mas para apenas $1 / 3$ desse percentual a concessão do benefício foi decisiva para a aprovação.

- Entre os estudantes que dependeram do bônus para serem aprovados, a maior proporção foi observada, de um lado, nos egressos de escolas estaduais e, de outro, nos que se declararam pardos. Os que se declararam brancos, por sua vez, foram beneficiados em maior proporção do que os que se declararam pretos.

- A implantação do programa de bônus parecer ter propiciado alteração no perfil dos aprovados no vestibular. O número de estudantes que fizeram o ensino médio em escolas públicas aumentou, bem como o dos que se declararam pretos e pardos e daqueles com renda familiar média de até 5 SM. Isso ocorreu inclusive em carreiras tradicionais e de maior prestígio social.

- A implantação do programa de bônus teria aparentemente contribuído mais do que a expansão de vagas para a inclusão de estudantes de escolas públicas. O contrário parece ter ocorrido com aqueles que foram incluídos em razão de sua declaração de cor ou raça.

Cabe observar existirem indicações de que o programa de bônus estaria induzindo os candidatos a mudarem o perfil da declaração de cor ou raça, fato que já ocorria anteriormente sem a existência do bônus. Essas mudanças não encontram respaldo nos dados produzidos por eles em relação a outras variáveis informadas no questionário do vestibular, não sendo possível afirmar, por isso, serem essas alterações efetivas. 
Ou seja, os estudantes podem estar mudando a declaração devido ao bônus, mas isso pode estar ocorrendo também por outras razões ainda não totalmente esclarecidas.

Por fim, o sucesso das ações afirmativas como mecanismos de promoção da inclusão na sociedade depende não apenas do oferecimento de oportunidades educacionais pelas instituições, havendo questões que dependem diretamente da atuação dos próprios beneficiários dessas ações. Não pode ser desconsiderado o importante papel a ser cumprido nesse processo pela

habilidade dos beneficiários em aproveitar eficazmente as oportunidades educacionais criadas para desempenhar bem suas atividades acadêmicas e, eventualmente, trabalhos de elevada produtividade e salário que poderiam alcançar após a graduação. (Zoninsein, 2006, p. 71).

Este é um ponto crucial do processo, mas que escapa à esfera das ações coletivas e institucionais. Do ponto de vista institucional, precisam ser implementadas ações de assistência estudantil, indispensáveis para apoiar o desempenho do estudante beneficiado durante sua permanência na universidade. No caso da UFMG, pelo menos parte dessas questões poderá ser atendida por meio das ações que são conduzidas pelos seus programas de assistência estudantil. A Universidade conta com uma fundação, criada nos primórdios de sua existência, voltada para esse atendimento. Cabe avaliar até que ponto ações do tipo das que são disponibilizadas pela UFMG cumprem, de fato, o papel que delas é esperado dentro do leque amplo de necessidades financeiras e pedagógicas compreendidas no problema aqui analisado.

\section{Referências bibliográficas}

BOBBIO, Norberto. Igualdade e liberdade. 2. ed. Rio de Janeiro: Ediouro, 1997.

BRAGA, Mauro M.; PEIXOTO, Maria do Carmo L. Censo socioeconômico e étnico dos estudantes de graduação da UFMG. Belo Horizonte: Ed. UFMG, 2006.

. Expansão dos cursos noturnos na UFMG: uma política efetiva de inclusão social? In: PEIXOTO, Maria do Carmo L.; ARANHA, Antônia (Orgs.). Universidade pública e inclusão social, experiência e imaginação. Belo Horizonte: Ed. UFMG, 2008. p. 92-118.

FERES JR, João; ZONISEIN, Jonas. Introdução: ação afirmativa e desenvolvimento. In: FERES JR, João; ZONINSEIN, Jonas (Orgs.). Ação afirmativa e universidade, experiências nacionais comparadas. Brasília: Ed. UnB, 2006. p. 9-45. 
MOEHLECKE, Sabrina. Ação afirmativa no ensino superior: entre a excelência e a justiça racial. Educação \& Sociedade, Campinas, v. 25 n. 88, especial, p. 757-776, out. 2004. Disponível em: <http://www.scielo.br/pdf/es/v25n88/a06v2588.pdf>.

PEIXOTO, Maria do Carmo. Inclusão social na educação superior. Série-Estudos, Campo Grande, n. 30, p. 1-34, jul./dez. 2010.

WANDERLEY, Sônia. Aprendendo a conviver com as diferenças, a introdução do sistema de cotas na Uerj. In: PEIXOTO, Maria do Carmo L.; ARANHA, Antônia (Orgs.). Universidade pública e inclusão social, experiência e imaginação. Belo Horizonte: Ed. UFMG, 2008.

p. 169-201.

ZONISEIN, Jonas. Minorias étnicas e a economia política do desenvolvimento: um novo papel para universidades públicas como gerenciadoras da ação afirmativa no Brasil? In: FERES JR, João; ZONINSEIN, Jonas (Orgs.). Ação afirmativa e universidade, experiências nacionais comparadas. Brasília: Ed. UnB, 2006. p. 63-78.

Maria do Carmo de Lacerda Peixoto, doutora em Educação pela Universidade Federal do Rio de Janeiro (UFRJ), é professora da Universidade Federal de Minas Gerais (UFMG).

mcarmo@ufmg.br

Mauro Mendes Braga, doutor em Química pela Universidade Federal de Minas Gerais (UFMG), é professor da Universidade Federal de Minas Gerais (UFMG).

braga@ufmg.br

Recebido em 20 de abril de 2011.

Aprovado em 8 de fevereiro de 2012. 